\title{
Family Business Transfer: The Importance of Continuing the Business
}

\author{
Paulino Silva, Rui Silva* \\ Polytechnic Institute of Porto - School of Accounting and Administration (ISCAP-IPP) \\ *Corresponding Author: ruisilva@iscap.ipp.pt
}

Copyright $@ 2014$ Horizon Research Publishing All rights reserved.

\begin{abstract}
This paper is about business transfer in family businesses companies. The problem of succession in family businesses in Portugal gets special interest given the high number of these companies. The field study uses interviews from five cases studies which were in a succession process. To help in the succession process is important to take into account the succession plan role and all problems that can happen during the process. The succession plan is the most important instrument in the succession process. It should be done on time to prepare conveniently whom is the successor, when and how the succession takes place. Even though, our evidence suggests that succession can be successful, even without a formal succession plan.
\end{abstract}

Keywords Succession, Family Business, Succession Plan

\section{Introduction}

Family businesses are about $65 \%$ to $80 \%$ of the enterprises worldwide [1]. Therefore, this is a topic of particular relevance to study.

Our study discusses the topic of family business and its importance in regional development and competitiveness in Portugal. Similarly to what happens in other European countries, the number of small and medium enterprises (SMEs) is overwhelming. In a study by IAPMEI [2]in February 2008, indicates that SMEs account for $99.6 \%$ of business units - companies - of the country, creating three quarters $(75.2 \%)$ of the total jobs, and representing more than half of the total sales $(56.4 \%)$. These figures are a quite enlightening overview of the Portuguese private sector and the importance of SMEs.

This research focuses on a case study of five SMEs, which are or were in a succession process. We expected to get answers about how and in what way these companies are dealing with the issue of succession. The survival and continuity of these companies is very important for the country because if the companies go bankrupt there are losing of jobs just to mention one of the reasons.
This study investigates how the succession process is conducted within the companies using the frameworks presented by other researchers.

To achieve these purposes, the following questions have been developed:

- Is there a succession plan to implement or that is being implemented?

- How the succession process is conducted in the company?

- Do you want to see your business continuing in family's property?

\section{Objectives}

The main objectives of this research are to summarize the owners of family businesses to the need for business continuity. The continuity of family businesses, in which Portugal has a very high weight in total businesses, it is critical for the country and the continued maintenance of all investment.

\section{Materials and Methods}

In this chapter we give a brief review of the literature. One of the most important aspects in a succession of a familiar business is succession planning. Lansberg stated that the lack of succession planning has been identified as one of the most important reasons why many first-generation family firms do not survive their founders. This failure is intimately linked to the problem of dependence on the control of the company and know-how of the business, which is owned by its founders [4]. The succession is not a simple process but a process with multiple steps, which begins long before entering the heirs of the company [5].

In this paper we discuss five fundamental aspects that think within the family businesses, which are: succession as a process, the role of the founder, the perspective of the next generation, multiple levels of analysis and the characterization of effective successions. 


\subsection{Theoretical Base}

\subsubsection{The Oldest Family Businesses}

We begin for transmitting the idea that many of the family businesses currently have a short life, because there are few who survive more than the first generation. But we risk stating that much of what we say below can be a surprise. In the list of the 100 oldest family businesses around the world, there are two Portuguese companies. The oldest family business in the world is Japanese. This old company is a hotel, founded in 718 and is now in its 46th generation, called Houshi Hotel and is listed in the Guinness Book of World Records. The UK in turn is the country with the most companies listed on the list of the 100 oldest family businesses, with 24 companies, followed by France with 19 and Italy with 17 companies. The two national companies are: JB Fernandes and Sons, Ltd., founded in January 12, 1781 by Ignacio Jose Fernandes and dedicated to the iron trade, hardware \& tools. The second oldest family-owned company was founded in 1792 by Jerónimo Martins and today is one of the main Portuguese economic groups. In his "tent" as it was called at the time, sold a bit of everything: sausages, sacks of wheat and corn, sauces tallow candles, wine, brooms, etc [3].

\subsubsection{Family Business}

In order to facilitate interpretation over the years in family businesses, some models have been developed. Of the various models that were developed, one that stands out is the three-circle model. This model is one of the most used and cited. This model was an evolution of the model created by Tagiuri and Davis, the two circles result of work done at Harvard in the early 80 's. This model is known by the three circles model. Through the interpretation of this model wecan identify many sources of problems, especially those areas where there are intersections of the circles (Figure 1).

There are many authors who have used these fundamentals to create models of family business succession. A brief literature review focused on some of these models of family business succession.

Given the importance of family businesses in the European economy the definition of family business is not yet institutionalized, as with the definition of SMEs, which has been defined by the European Union, and has already stated in our introduction. Such companies have huge meanings that once concentrated two of the most important values in western societies: family and private property [6]. Neubauer shows us some important characteristics of family businesses. These characteristics are, own an unique history, culture and its own specific characteristics.

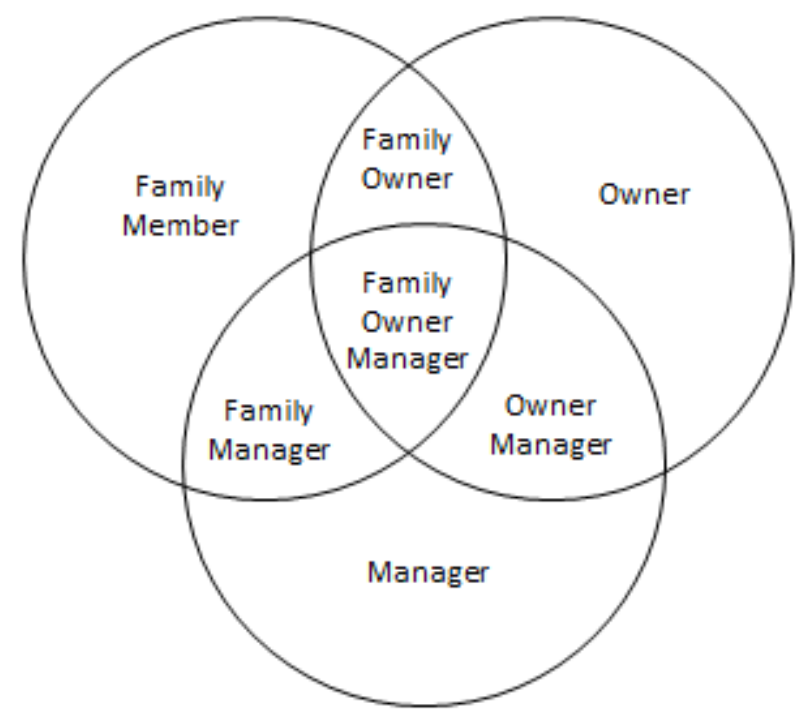

Figure 1. The three circle model of family business (Gersick, et al. 1997: p. 6)

In this model we have seven different situations, which imply different consequences to the succession plan, but in one first approach we have three different concepts: business management, property and the family. With these concepts it's possible to have people with only one connection (this appears when one person stays at one of the three possibilities: Family Member, Owner or Manager). Another possibility appears when some have two connections to the company (this appears when one person stays at one of the three possibilities: Family Owner, Family Manager or Owner Manager). Finally we have the most complex situation, that happens when a person stay in middle of the model. In that position we have someone at the same time is member of the family, owner and manager. Of these different intersections visible in the model, conflicts can arise that must be wary not to pose a barrier to succession.

\subsubsection{Succession Development}

Succession is the process that has an objective, ensuring the business in the family [7]. The succession represents a process that starts by a long period of time before the successors enter the firm [8]. We decide present the next model because the succession process it's very complex and this model show the complexity of the process.

We will then present the model proposed by Cabrera-Suarez in figure 2[9]. 


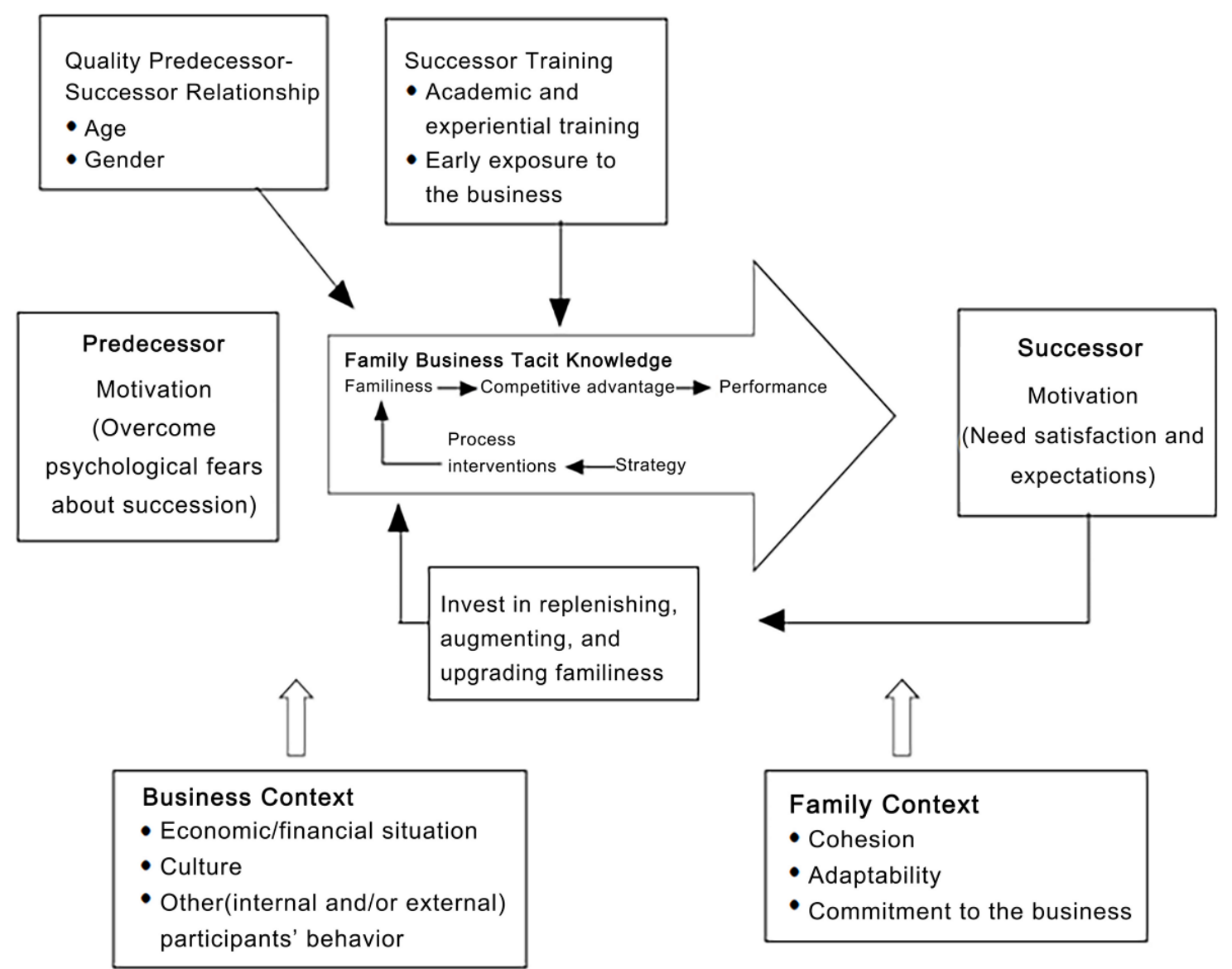

Figure 2. Model of Knowledge Transfer and Successor's Development in the Family Firm (Cabrera-Suarez 2001)

This model represents the main factors to take into consideration on a process of succession, since selection of the successor, training, motivation of the successor and the predecessor, the business context and the family context. These factors are very important to the process of succession to succeed. Regarding the first factor, selection of a successor, we like to highlight one aspect that is about the gender. In the socialization process, young girls are often treated differently than their brothers [5].

The series resistance is often linked to various types of retirement of the predecessor. Handler citing Sonnenfeld identified several types of predecessors: Monarchs, Generals, Ambassadors and the Governors. Levinson [10], we used three types of predecessor loyal servant, watchful waiter and false prophet. These type definitions are very important predecessor to understand the various types of resistance to succession.

Howorth [11] in her study concluded that the interviewees expressed a preference for type founding monarch and showed great difficulty in accepting mortality. This conclusion is very important to us, since the study was conducted in Portuguese companies. Another interesting conclusion that the authors reached was that the reasons for resistance are equal to other cultures.

\subsubsection{Succession Planning}

Neubauer [6] breaks down the barriers to succession into three broad groups: personal barriers, business-related and general barriers. In personal barriers are: acceptance by employees of successor, successor by acceptance of business partners, limited management experience of successor, limited professional and qualifications of successor's successor lack of a business degree. With regard to business-related barriers have, problems broken down into can be the areas of suitability for a successful transfer, prospects of success in the respective industry, and financing requirements for the takeover. In general barriers we have: the product or service range no longer meets the market's requirements, the business location is unfavorable especially in retail trade (lack of customer frequency), the business is in an industry that is not very promising for the future and/or the business' size is poorly suited to its field of business activity, management styles and structures are outdated, neglect or postponement of investment often means lower productivity and/or lower product or service quality.

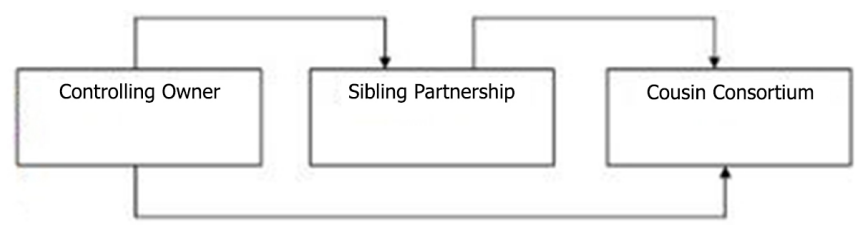

Figure 3. Three types of leadership (Gersick, et al. 1997: p. 31) 
Lambrecht [12], identified six key steps to transfer the business: to be successful, entrepreneurship, studies, formal internal education, external experience, official start in the family business: bottom of the ladder and freedom for and by the successor(s), written plan and agreement. For the studies, Howorth [11] found something interesting. In families that have at least one daughter and a son, daughter has a higher level of education, typically college, while the boy is by the high school. This scenario is already better than the level of education of the father who is usually up by low levels of education.

Another factor which we find very important to mention is the way to control the company and the distribution of leadership. According to Gersick [1] presents three types of leadership. Schematically appears to us as follows:

Another model of succession planning that we consider it crucial to mention is that developed by Bareither [13]. This is based on three phases, nine steps and three benefits. The phases are: phase 1 - examine current plan, phase 2 develop new plan and phase 3 - present new plan. Regarding the steps we have: step 1 - interview individual family members, step 2 - determine family objectives, step 3 - analyze current plan, step 4 - determine alternate transfer options, step 5 - seek advisor input, step 6 develop new plan, step 7 - present new plan, step 8 consider liquidity options and the last step - implement and monitor new plan. In last we have the benefits. Benefit $1-$ minimize IRS role, benefit 2 - enhance family communication and benefit 3 - maximize business profitability.

However, research on family firms in Portugal is virtually nonexistent. Portugal in cultural terms is very similar to Anglo-Americans [11].

\subsubsection{Succession Process Variables}

The existence of unique features means that there are many variables in such companies. Thus, we must take into account a range of variables usually found in family businesses. The authors Breton-Miller[7] did a survey on the variables most frequently cited in the literature, which are presented in Table 1.

\subsection{Empirical Research}

\subsubsection{Methodology}

The research work mainly intends to understand how family-owned SMEs make the succession transfer process. The research design entails five case studies from Portugal, four from the northern region and another from the center region. In this investigation we conducted interviews with predecessors and successors, as these are the main actors in a succession process.

Regarding the interviews, in order to assure methodological validity, we used also observation method [14]. According to Marginson [15] interviews can be structured, semi-structured or unstructured. In our research we used semi-structured interviews.
Table 1. Succession Process Variables mentioned most in the literature (Le Breton-miller 2004)

\begin{tabular}{|c|c|c|}
\hline & $\mathrm{N}=$ & $\%$ \\
\hline \multicolumn{3}{|l|}{ Incumbent } \\
\hline - $\quad$ Motivation/Willingness & 23 & 49 \\
\hline $\begin{array}{l}\text { - Quality incumbent-successor relationship (respect, } \\
\text { understanding, trust, cooperation }\end{array}$ & 23 & 49 \\
\hline - $\quad$ Personality, needs & 17 & 36 \\
\hline \multicolumn{3}{|l|}{ Successor } \\
\hline $\begin{array}{l}\text { - Quality incumbent-successor relationship (respect, } \\
\text { understanding, trust, cooperation \& closeness) }\end{array}$ & 23 & 49 \\
\hline $\begin{array}{l}\text { - Motivation (interest, commitment to FOB } \\
\text { perpetuation as a family value, freedom not to join } \\
\text { FOB) }\end{array}$ & 20 & 43 \\
\hline $\begin{array}{l}\text { - Management ability, competence, talent, experience, } \\
\text { drive, credibility \& legitimacy }\end{array}$ & 17 & 36 \\
\hline Nurturing/Development of successor(s) & 13 & 28 \\
\hline $\begin{array}{l}\text { - } \quad \text { Career development, early exposure to the business \& } \\
\text { growing involvement }\end{array}$ & 18 & 38 \\
\hline - $\quad$ Outside work experience & 18 & 38 \\
\hline $\begin{array}{l}\text { - Apprenticeship (transfer of knowledge — explicit \& } \\
\text { tacit—\& contacts) }\end{array}$ & 16 & 34 \\
\hline - $\quad$ Formal education program & 15 & 32 \\
\hline - $\quad$ Training program & 12 & 26 \\
\hline \multicolumn{3}{|l|}{ Family dynamics } \\
\hline $\begin{array}{l}\text { - Collaboration, accommodation, team approaches } \\
\text { rather than conflict-rivalry, harmony, quality of sibling } \\
\text { relationships }\end{array}$ & 17 & 36 \\
\hline \multicolumn{3}{|l|}{ Hand-off/Transition Process/Installation } \\
\hline - Incumbent phase out/transition \& new role & 18 & 38 \\
\hline - $\quad$ Successor phase in (COO, CEO, chairman) & 13 & 28 \\
\hline \multicolumn{3}{|l|}{ Ground rules \& 1st steps } \\
\hline - $\quad$ Succession planning & 16 & 34 \\
\hline - $\quad$ Shared vision for the future to establish & 14 & 30 \\
\hline $\begin{array}{l}\text { - } \quad \text { To be established early, clearly, communicated \& } \\
\text { adjusted with feedback }\end{array}$ & 13 & 28 \\
\hline - $\quad$ Time frame \& timing & 12 & 26 \\
\hline Board of directors & 15 & 32 \\
\hline - Composition & 12 & 26 \\
\hline
\end{tabular}

This study was conducted through interpretive research. Interpretative research does not intended to generalize or predict future phenomena based on the present studies, but only perceive the events of everyday life, social structures, as well as the meanings people attribute to it. In addition searching also understands the behavior of individuals in a certain context. This means finding structures in their social context and understands how they evolve over time [16].

\subsubsection{Data}

Data collection was performed in addition to the aforementioned, by conducting interviews and varied documentation, including reports and accounting records..The document collection was extremely important for this research. The documents consulted enriched the research and helped that the conclusions were stronger. 
All interviews were recorded for later analysis, in audio and in one of our cases in video. We also collected other information about the five companies.

Table 2. Duration of the interviews and interviewees

\begin{tabular}{|c|c|c|c|c|c|}
\hline & Case 1 & Case 2 & Case 3 & Case 4 & Case 5 \\
\hline Interview & CEO & Family & $\begin{array}{c}\text { CEO and } \\
\text { two } \\
\text { daughters }\end{array}$ & $\begin{array}{c}\text { CEO } \\
\text { and one } \\
\text { brother }\end{array}$ & CFO \\
\hline Duration & $33 \mathrm{~m}$ & $1 \mathrm{~h} 45 \mathrm{~m}$ & $1 \mathrm{~h} 30 \mathrm{~m}$ & $1 \mathrm{~h} 30 \mathrm{~m}$ & $1 \mathrm{~h} 45 \mathrm{~m}$ \\
\hline
\end{tabular}

The fact of having more than one method of data collection, permitted to use a technique used, giving more strength and robustness of research, is called triangulation data [17].

The existence of various sources of data enabled triangulation data, which is a fundamental for the use of case studies [18].

\subsubsection{Discussion}

Analysis to date we started to highlight some statements we find very important for our research.

In the first case we find evidence of the existence of a succession plan perfectly delineated, with all the owners aware of the importance of the process to prepare in advance and with external consultants to prepare a succession plan.

In the second case the predecessor said:

"Although it has not transferred ownership of the company to my sons, in practice it is as if he had. My oldest son already has a joint management of the company and it is his responsibility to decision-making everywhere financial and Investment Company. My responsibility at this point is more the logistics, but my son always ask me opinion on some investments, I am aware that he knows that better than me."

The father also said that:

"The daughters work more than 200kms and have both their own business and no longer want to know the father's business. However his father wanted is the business to continue in some way"

In the third case the resignation of the owner regarding the "death" of the business is almost final and not put the hypothesis to sell or use professional management for the company, thus maintaining the property in the family. The owner said:

"I think any of my daughters wants to follow the business. The only daughter who could was my middle daughter, she works with me, but neither wants to follow this business. Currently also do not know whether it is good for any of them follow the business. Now of course one of them liked to continue the work I started, but I think it will not happen. "

In our fourth case was also one where the succession process has already started and two of the three sons were already in the business of the company. The oldest son is one of the managers of the company and another son performs administrative functions in the company.
In the fifth case the predecessor is very concerned about his succession. The CFO said:

"The daughters work more than 200kms and have both their own business and no longer want to know the father's business. However his father wanted is the business to continue in some way."

In all cases, we had access to documents that helped us to validate the conclusions obtained.

\subsubsection{Linking the Results to the Theoretical Models} Presented

In the case number one we have a formal process for succession with professional advisers (external consultants). With the interview it was possible made the connection to the model presented in the figure 4, because the CEO described to the researchers, the entire process and many other aspects that match with the model of Bareither. An important information collected by the researchers, was the experience of the first succession process, that was very useful to the CEO be aware of the importance to prepare the process as soon as possible and use the skills of expertise people, to help the company during the entire process.

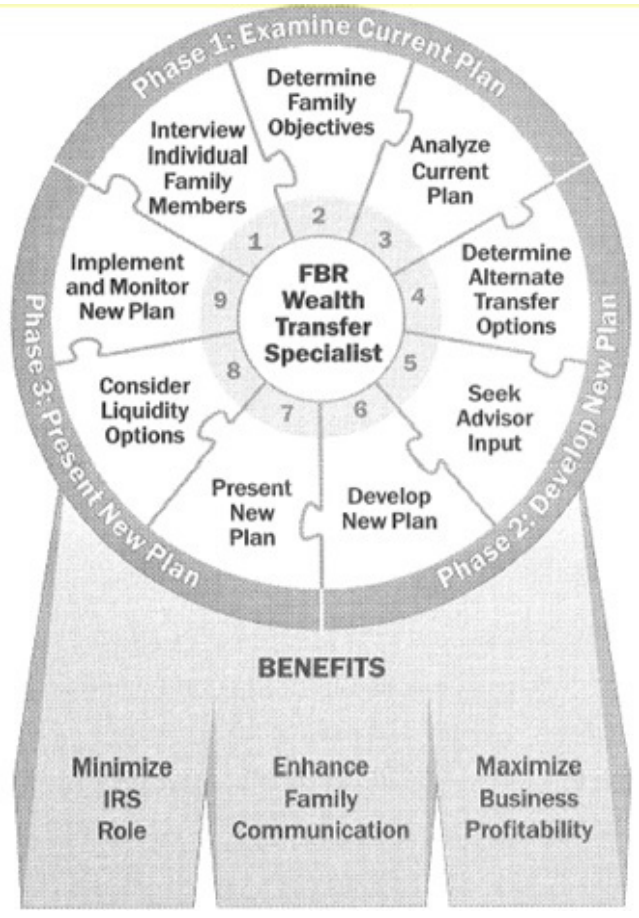

Figure 4. Model of succession planning by Bareither (2003, p: 140)

In the case number two, which was the most important case presented in this research, and it was the most important because had a set of circumstances to the succession fail but didn't failed. Although the company didn't followed any formal plan, didn't asked or having resorted to an specialist, in order to get advice, the succession process was and continue taking place following an informal model, but with many common points to a formal model, like the model presented in figure 2. In this case all family members know exactly what they want to 
the family business, including all important points such the economic, financial and tax aspects that are important to be successful.

In the case number four they started the process of the succession without a formal model, like happened in the case number two. However there were many differences between these two cases such as, the dimension, the number of employees and the high number of competitors. The company described in case number two is much more complex than the company described in the case number four. In this case we cannot make any connection to a theoretical model but we found evidence that the succession process until the moment was successful.

The last two cases, numbers three and five, were very similar, because the continuity of the business is in high risk. The main reason for this situation was the indifference of the successors inside the family. Therefore, the linking to theoretical models wasn't possible.

\subsection{Results}

The succession process in a company still is uncomfortable, but very important to its predecessor. The succession plan continues to be informal or non-existent in most of our cases studies. In the second and fourth cases, the succession process already started, but without a succession plan. In the fifth case, there is also no succession plan, but the predecessor was the only one that wanted the succession. The heirs did not want the succession takes place. The third case is the most worrying because no solution was found. That is why this kind of research is necessary to sensitize the owners for the existence of solutions and show the advantages that exist in business continuity. Finally, the first case is good example of how to make the succession planning. The owners had a clarity and information above average about the need to prepare the succession and about the advantages for everyone involved in the business continuity and even with the use of external consultants, so that the succession plan is the most complete and effective for the company.

\section{Conclusions}

The first conclusion is the need for the existence of a succession plan, formal or informal, to make possible to maintain the business in the family.

Another conclusion is the existence of the alternative path to the succession, transfer of ownership or the admission of professional management solutions are liable to be taken into account when the succession is not applicable.

This study is limited because only five companies had been examined and it is limited to Portugal.

With this research we hope help the owners of family businesses of the importance of succession planning and show other ways of transmitting business without being by way of succession.

For future research, we suggest the replication of this study in a higher number of companies and in other countries.

\section{Acknowledgements}

We would like to thank to all interviewees for their availability to participate in this research.

\section{REFERENCES}

[1] K. E. Gersick, J. A. Davis, M. M. Hampton, and I. Lansberg, Generation to Generation - Lyfe Cycles of the Family Business. Harvard Business School Press, 1997, pp. 1-299.

[2] IAPMEI, "Sobre as PME em Portugal," 2008.

[3] B. W. T. O. Hara and P. Mandel, "The World' s Oldest Family Companies," 2001.

[4] I. Lansberg, "The Succession Conspiracy," Fam. Bus. Rev., vol. 1, no. 2, pp. 119-143, Jun. 1988.

[5] W. C. Handler, "Succession in Family Business: A Review of the Research," Fam. Bus. Rev., vol. 7, no. 2, pp. 133-157, Jun. 1994.

[6] H. Neubauer, "The Dynamics of Succession in Family Businesses in Western European Countries," Fam. Bus. Rev., 2003.

[7] I. Le Breton-miller, D. Miller, and L. P. Teier, "Toward an Integrative Model of Effective FOB Sucession," Entrepr, no. 4, pp. 305-328, 2004.

[8] W. C. Handler, "Succession in Family Firms?: A Mutual Role Adjustment between Entrepreneur and Family Members," no. 1971, pp. 37-52, 1990.

[9] K. Cabrera-Suarez, P. Saa-Perez, and D. Garcia-Almeida, "The Succession Process from a Resource- and Knowledge-Based View of the Family Firm," Fam. Bus. Rev., vol. 14, no. 1, pp. 37-48, Mar. 2001.

[10] H. Levinson, "Don't Choose Your Own Successor," Harv. Bus. Rev., vol. 52, no. 6, pp. 53-62, 1974.

[11] C. Howorth and Z. A. Ali, "Family Business Succession in Portugal: An Examination of Case Studies in the Furniture Industry," Fam. Bus. Rev., vol. 14, no. 3, pp. 231-244, Sep. 2001.

[12] J. Lambrecht, "Multigenerational Transition in Family Businesses: A New Explanatory Model," Fam. Bus. Rev., vol. 18, no. 4, pp. 267-282, Dec. 2005.

[13] K. Bareither and T. Reischl, Planning a Family \& Business Legacy. Family Business Review System, 2003, pp. 1-207.

[14] J. Mason, Qualitative Researching. Sage Publications, 2002, pp. 1-225.

[15] D. E. W. Marginson, "The case study, the interview and the issues?: a personal reflection," in in The real life guide to 
accounting research?: a behind the scenes view of using qualitative research methods, Oxford: CIMA Publishing, 2008, pp. 325-337.

[16] B. Ryan, R. W. Scapens, and M. Theobald, Research Method and Methodology in Finance and Accounting. Academic Press, 1998.

[17] S. Modell, "In defence of triangulation: A critical realist approach to mixed methods research in management accounting," Manag. Account. Res., vol. 20, no. 3, pp. 208-221, Sep. 2009.

[18] S. Modell, "Triangulation between case study and survey methods in management accounting research: An assessment of validity implications," Manag. Account. Res., vol. 16, no. 2, pp. 231-254, 2005. 